\title{
On factors affecting surface free energy of carbon black for reinforcing rubber
}

https://doi.org/10.1515/ntrev-2020-0015

Received Nov 10, 2019; accepted Dec 04, 2019

\begin{abstract}
The surface activity of carbon black (CB) is an important factor affecting the reinforcement of rubber. The quantitative determination of the surface activity (surface free energy) of CB is of great significance. A simplified formula is obtained to determine the free energy of CB surface through theoretical analysis and mathematical derivation. The surface free energy for four kinds of industrial CBs were measured by inverse gas chromatography, and the influential factors were studied. The results showed that the aging time of the chromatographic column plays an important role in accurate measurement of the surface free energy of $\mathrm{CB}$, in comparison with the influences from the inlet pressure and carrier gas flow rate of the chromatographic column filled with CB. Several kinds of industrial $\mathrm{CB}$ were treated at high temperature, and the surface free energy of CB had a significant increase. With the increase of surface free energy, the maximum torque was decreased significantly, the elongation at break tended to increase, the heat generation of vulcanizates was increased, and the wear resistance was decreased.
\end{abstract}

Keywords: carbon black; surface free energy; rubber

\section{Introduction}

As an industrial raw material, carbon black (CB) is a fluffy black powder with diameter of small size. It is widely used for various applications such as reinforcement for rubber [1], anti-aging and anti-static additives for plastic [2], anode materials for lithium ion battery [3-5], support for catalyst [6], pigment for printing and dyeing industries [7],

\footnotetext{
${ }^{\star}$ Corresponding Author: Ruoyu Hong: College of Chemical Engineering, Fuzhou University. Fuzhou, China, 350108; Email: rhong@fzu.edu.cn
}

Shangyong Zhang, Ruipeng Zhong: College of Chemical Engineering, Fuzhou University. Fuzhou, China, 350108

David Hui: Department of Mechanical Engineering, University of New Orleans, New Orleans, LA 70148, United States of America etc. Recently, some literatures have reported that the carbon fibers or graphene were used as reinforcing agents for rubber. However, due to the high cost and low reinforcing effect, they have not been widely used [8]. In fact, the CB used for reinforcing rubber occupies its $94 \%$ production in industry.

According to previous studies, the particle size, structure and surface activity of $\mathrm{CB}$ are the main factors that affect the reinforcement of rubber. In the chemical sense, the surface activity of $\mathrm{CB}$ depends on different chemical groups attached on the surface, such as carboxyl, hydroxyl, quinonyl and lactone [9]. In the physical sense, it is reflected by the surface free energy of CB, especially its non-polar parts, that is, the dispersive free energy. Due to the high surface activity and small size, $\mathrm{CB}$ is prone to agglomerate, making it difficult to disperse in some polymer matrices. As a polar inorganic particle, it is also difficult to disperse uniformly in some non-polar or low polar rubbers, such as styrene-butadiene and butadiene rubbers. The dispersion of CB affects the performance of its properties and limits its varieties of applications. Therefore, the surface of CB is generally modified by chemical or physical methods before being used to meet the actual needs. The major modification methods include dispersant treatment, surface oxidation, surface graft and plasma [10-14]. Through surface modification, the surface free energy of $\mathrm{CB}$ will be changed accordingly to meet the specific requirements. For example, hydrophilic groups such as carboxyl and hydroxyl are formed on the surface of CB by oxidation treatment, which enhances the dispersion of $\mathrm{CB}$ in aqueous solution [15]. It can reduce the intermolecular force and improve the compatibility of $\mathrm{CB}$ and medium by the graft modification.

Previous studies $[16,17]$ showed that the bound rubber has a crucial influence on the CB-reinforced rubber, while the bound rubber is affected by the surface activity of $\mathrm{CB}$. The disfigurements of structure, impurity, hydrogen and chemical groups on the surface of $\mathrm{CB}$ are all accessible positions with high activity, and some of these positions plays an important role [18]. The reduction of highly active positions will decrease the amount of bound rubbers, leading to the decrease of stress at definite elongation, ten- 
sile strength, abrasion resistance, and increase of $\tan \delta$ of gross rubber [19]. The study on the surface activity of CB is indispensable. However, there is little study on the surface free energy of $\mathrm{CB}$, and most of the previous studies only focused on the investigation of structural and functional groups of CB.

At present, the main calculation model of surface free energy is the Owens-Wendt-Rabel-Kaelble (OWRK) model, which is based on Fowkes' sum rule of solid surface free energy. The surface free energy can be divided into the dispersive and the polar components, reflecting the different molecular types of forces [20-22]. The main methods used to determine the surface free energy are inverse gas chromatography (IGC) and contact angle measurements [23, 24]. In the contact angle measurement, the dispersive and polar components of the surface free energy are calculated by measuring the contact angles of a known small molecular liquid with solid material. However, the users sometimes were perplexed by the unreproducible values under repeated measurements and the high requirement of samples preparation $[25,26]$.

The IGC is one of the simplest and most reliable methods to measure the surface properties of materials, and hence widely used for providing information about some surface physicochemical properties such as diffusion kinetics, surface energy heterogeneity, polar functionality and so on. This chromatographic method is different from the conventional gas chromatography. Prior to test, the sample is used as a stationary phase, and the known small molecular liquid is used as the probe molecule. The gasification probe molecules are taken into the chromatographic column by the carrier gas under certain conditions. The surface free energy of the stationary phase is studied by measuring the retention time of the probe molecules required to pass through the chromatographic column $[27,28]$. Compared with the contact angle measurement, no special sample preparation and elaborated apparatus are needed, so accurate measurements are possible over a wide range of temperatures [27]. The sample could be nanoparticles, a fibrous composition, polymer and so on $[29,30]$.

High surface activity is the main feature of $\mathrm{CB}$, different from other fillers, which has an essential effect on the interaction between filler surface and polymer matrix. Therefore, accurate determination of the surface activity (surface free energy) of CB becomes important. However, there is still limited study on the factors affecting the surface activity evaluated by inverse gas chromatography.

In this study, the effects of carrier gas flow rate, inlet pressure and aging time of the packed column on the surface activity of various CB samples are systematically stud- ied through theoretical analysis and experimental verification. Moreover, the surface free energy of CB treated at different temperature was measured using the inverse gas chromatography. The performance of the rubber filled by the treated CB was investigated.

\section{Experimental}

\subsection{Materials and methods}

The CB samples A, B, C, D, N234, N375, N550 and N660 are all industrial CB from Suzhou Baohua Carbon Black Co., Ltd. The insoluble sulphur with the size of 200 mesh was obtained from Eastman. Styrene-butadiene rubber (SBR) was supplied by Baling Petrochemical Company. The probe molecules: $n$-pentane, $n$-hexane, $n$-heptane, $n$ octane and acetone are all chromatographical grade.

The following apparatus were used: Box type atmosphere furnace (JQF1400-40, Shanghai Jigong Electric Co., Ltd.), Gas chromatograph (GC-17A Gas Chromatograph, Shimadzu), Data acquisition (CSC-100D, Beijing Huibo Elite Technology Co., Ltd.), Twin-roll mill for rubber (XK152.5, Guangdong Zhanjiang Experimental Machinery Factory), Internal mixer (Haake Torque Rheometer with a volume of $500 \mathrm{~mL}$, Thermo Fisher Scientific Inc.), Flat vulcanizing machine (630kN, Huzhou Rubber Machinery Co., Ltd.), Pneumatic automatic slicer (GT-7016-AR, High-Speed Rail Testing Instrument Co., Ltd.), Electronic universal material testing machine (double column desktop 2365, Instron Corporation), Rubber processing analyzer (RPA2000, Alpha), Rotorless vulcanizer (MRD2000, Alpha), Mooney viscometer (MV2000, Alpha), Akron grinding machine (High-Speed Rail Testing Instrument Co., Ltd.), and Compression Heat Test Machine (GT-RH-2000, High-Speed Rail Testing Instrument Co., Ltd.).

\subsection{Heat treatment of $C B$ in vacuum}

In order to avoid the oxidization of CB by air, the untreated sample N375 was placed in a tube furnace connected to a vacuum pump. The $\mathrm{CB}$ sample was heated in the vacuum tube at $300^{\circ} \mathrm{C}$ for $1 \mathrm{~h}$. After that, the sample was cooled down to room temperature, subsequently taken out from the vacuum tube and kept in a vacuum dryer. 


\subsection{Experimental condition for inverse gas chromatography}

The stainless columns with $2 \mathrm{~mm}$ inner size and $30 \mathrm{~cm}$ long were chosen for the measurement of $\mathrm{CB}$ surface free energy. The packed column filled with $\mathrm{CB}$ was installed in the gas chromatographic system. The air tightness was checked first, then the pressure stabilizer was adjusted, and a soap film flow meter was used to measure the carrier gas flow rate corresponding to different column front pressures at room temperature. After that, the gas chromatograph, data acquisition and chromatograph workstations were switched on, so the rising temperature was programmed and stabilized at $180^{\circ} \mathrm{C}$. Then highly pure helium passed through the chromatographic column with the flow rate of $30 \mathrm{~mL} / \mathrm{min}$, aging for a certain period of time. Finally, a $1 \mu \mathrm{L}$ micro-injector was used to inject various probe molecules, including $\mathrm{n}$-hexane, $\mathrm{n}$-heptane and n-octane.

\subsection{CB surface free energy}

The surface free energy of CB is divided into two parts, nonpolar and polar components, and can be expressed by a formula: $r=r_{s}^{d}+r^{s p}$, where, $r$ represents the total surface free energy; $r_{s}^{d}$ represents a non-polar component of surface free energy, commonly referring to the dispersive free energy; $r^{s p}$ represents the polar component of surface free energy, namely the polar parameter. The dispersive free energy is closely related to the reinforcing capacity of CB.

\subsubsection{Nonpolar and polar components of CB surface free energy}

Calculation of retention volume $V_{N}[31]$

$$
V_{N}=D \cdot j\left(t_{r}-t_{m}\right)\left(1-p_{w} / p_{o}\right) \frac{T_{C}}{T_{f}}
$$

where, $V_{N}$ is the net retention volume, $D$ is the volume of carrier gas, $j$ is the gas compressibility factor, $t_{r}$ is the retention time, $t_{m}$ is the dead time, $p_{w}$ is the equilibrium pressure, $p_{o}$ is the pressure in the outlet of the column, $T_{C}$ is the column temperature, and $T_{f}$ is the flowmeter temperature.

The value of $j$ is given by [32]:

$$
j=\frac{\left(p_{i} / p_{o}\right)^{2}-1}{\left(p_{i} / p_{o}\right)^{3}-1} \times \frac{3}{2}
$$

where, $p_{i}$ is the pressure at the inlet of the column.

Calculation of adsorption energy $-\Delta G[21]$

$$
-\Delta G=R T \ln \frac{C V_{N}}{S g}
$$

where, $-\Delta G$ is the minus value of adsorption free energy, $R$ is the gas constant, $T$ is the column temperature, $C=299$, $S$ is the specific surface area of the filler, and $g$ is the mass of the filler in the column.

Calculation of $-\Delta G_{\mathrm{CH}_{2}}$

$-\Delta G_{\mathrm{CH}_{2}}$ is the free energy of adsorption per mole of methylene group, derived from the slope of the linear plot of $-\Delta G$ versus the carbon atom number of a series of $n$ alkanes probe molecules.

Calculation of $r_{s}^{d}$ [33]

$$
r_{s}^{d}=\left(\frac{-\Delta G_{C_{2}}}{2 N_{A} a_{C_{2}}}\right)^{2} \frac{1}{r_{C_{2}}}
$$

where, $r_{s}^{d}$ is the dispersive free energy, $-\Delta G_{\mathrm{CH}_{2}}$ is the free energy of adsorption per mole of methylene group, $N_{A}$ is the Avogadro's number, $a_{\mathrm{CH}_{2}}$ is the area covered by a - $\mathrm{CH}_{2}-$ unit, $0.06 \mathrm{~nm}^{2}, r_{\mathrm{CH}_{2}}$ is the surface energy of polyethylene, $35 \mathrm{~mJ} / \mathrm{m}^{2}$ [34].

Calculation of the polar part of adsorption free energy

Using the $-\Delta G$ of $\mathrm{n}$-alkanes to plot their molecular cross-sectional areas, a linear relationship is obtained. Then, the molecular cross-sectional area of the polar probe molecule is substituted into the relational formula to obtain the theoretical non-polar adsorption free energy of the polar probe molecule. Afterwards, the total free energy of the polar molecule minus the total free energy of non-polar part, that is, the polar part of its adsorption free energy, expressed as $-\Delta \Delta G$

Calculation of polar parameter of surface free energy $r^{s p}[33]$

$$
r^{S P}=\frac{-\Delta \Delta G}{N_{A} \cdot a_{p}}
$$

where, $r^{s p}$ is the polar parameter of surface free energy, $-\Delta \Delta G$ is the polar part of the absorbing free energy of the polar probe molecules and $a_{p}$ is the area occupied by a probe molecule on the $\mathrm{CB}$ surface.

\subsubsection{Theoretical deduction of CB surface free energy}

\subsubsection{Mathematical model}

During the measurement of surface free energy of $\mathrm{CB}$, each sample is tested under the respective column temperature, carrier gas flow rate, inlet pressure, etc.

First, suppose that $\mathrm{n}$-pentane, $\mathrm{n}$-hexane, $\mathrm{n}$-heptane and n-octane are corresponding to $x=5, x=6, x=7, x=8$, respectively, in that, $x$ is an independent variable which stands for different alkanes, and $t$ stands for the adjusted retention time, that is, $t=t_{r}-t_{m}$. Because different alkane results in a particular adjusted retention time, under fixed 
inlet pressure of column and volume of carrier gas, the correlation between $t$ and $x$ can be decribed as follows,

$$
t=t(x)
$$

According to formula (1), the relationship between adjusted retention volume and adjusted retention time can be expressed as follows,

$$
V_{N}=V(x)=D \cdot j\left(1-p_{w} / p_{o}\right) \frac{T_{C}}{T_{f}} t(x)
$$

According to formula (3), the relationship between Gibbs free energy and adjusted retention volume can be given:

$$
-\Delta G=-\Delta G(x)=R T \ln \frac{C V(x)}{S g}
$$

According to the definition of $-\Delta G_{\mathrm{CH}_{2}}$, it holds:

$$
-\Delta G_{C_{2}}=\frac{d(-\Delta G(x))}{d x}
$$

\subsubsection{Mathematical deduction}

Combination of formulas (5), (6), (7) and (8) results in:

$$
-\Delta G_{C_{2}}=R T \frac{d \ln t(x)}{d x}
$$

According to formula (4), the dispersive free energy $r_{s}^{d}$ is only dependent on $-\Delta G_{\mathrm{CH}_{2}}$, while formula (10) indicates that $-\Delta G_{\mathrm{CH}_{2}}$ can be derived from the slope of the linear plot of $\ln t(x)$ versus $x$. Meanwhile, formula (10) shows that the dispersive free energy is independent of the carrier gas flow rate and inlet pressure of the column. As a result, one can get the dispersive free energy easily from formula (10), and it is not necessary to make complicated calculation by formulas (1), (2) and (3).

\subsection{Gross rubber preparation and characterization}

The gross rubber was prepared by a two-stage process. The first stage of the mixing was performed in an Haake internal mixer at a speed of $60 \mathrm{r} / \mathrm{min}$ with the initial temperature of $90^{\circ} \mathrm{C}$. The rubber, additives and filler (CB) were added, and the temperature of the mixer is controlled at about $150^{\circ} \mathrm{C}$. The second stage of the mixing was performed in an open mill with twin-rollers. The above blended rubber, sulfur and accelerator were added into the open mill to obtain the gross rubber.

1. Vulcanization curve: The vulcanization curve of the gross rubber was obtained using a MRD2000 rotorless vulcanizer at the temperature of $150^{\circ} \mathrm{C}$ for 35 $\min$.
2. Mooney viscosity: The test was carried out using a disc-like viscometer according to the national standard GB/T1232.1-2000 which is similar to the ISO 2891:1994.

The specimens for other measurements were vulcanized using the gross rubber on a plate vulcanizer. The plate was heated by electrothermal calefactors at a temperature of $150^{\circ} \mathrm{C}$ and driven by hydraulic cylinder at a pressure of $10 \mathrm{MPa}$ for $90 \mathrm{~min}$. The performance of the specimens was tested after 24 hours (after vulcanization).

3. Tensile performance: The test was carried out using a universal material testing machine with the stretching speed of $500 \mathrm{~mm} / \mathrm{min}$ at room temperature according to $\mathrm{GB} / \mathrm{T} 528-2009$ which is similar to the ISO 37: 2005.

4. Tear resistance: The test was carried out using the machine with a stretching speed of $500 \mathrm{~mm} / \mathrm{min}$ at room temperature according to $\mathrm{GB} / \mathrm{T}$ 529-2008 which is similar to the ISO 34-1: 2004.

5. Hardness: The test was carried out using a hardness tester at room temperature according to GB/T 531.12008 which is similar to the ISO 7619-1:2004.

6. Rebound elasticity: The rubber elasticity tester was used at room temperature according to GB/T 16812009 which is similar to the ISO 4662: 1986.

7. Compressed heat generation: The compression heat generator was used at $(55 \pm 1)^{\circ} \mathrm{C}$. The specimen was preheated for $30 \mathrm{~min}$, compressed for $25 \mathrm{~min}$ with a frequency of $30 \mathrm{~Hz}$, stroke length of $4.45 \mathrm{~mm}$, pressure of $1 \mathrm{MPa}$, according to GB/T7759-1996 which is similar to the ISO 815:1991.

8. DIN wear: The specimen was tested using an abrasion machine with rotating rollers at room temperature according to GB/T9867-2008 which is similar to the ISO 4649: 2002.

\section{Results and discussion}

\subsection{Effect of inlet pressure on surface free energy}

Table 1 shows the dispersive free energy of samples A and $B$ at different inlet pressures. The Figures 1 and 2 show the relationship between the adsorption energy and carbon number of probe molecules. The column temperature was $180^{\circ} \mathrm{C}$, the carrier gas flow rate was $12.24 \mathrm{~mL} / \mathrm{min}$ and the aging time was $12 \mathrm{~h}$, while the inlet pressures of column was varied. 
Table 1: $r_{s}^{d}$ at different inlet pressures of column

\begin{tabular}{cccc}
\hline Sample & $p_{i}(\mathrm{kPa})$ & $r_{s}^{d}\left(\mathrm{~mJ} / \mathrm{m}^{2}\right)$ & Error \\
\hline \multirow{2}{*}{ A } & 30 & 85.05 & $2.17 \%$ \\
& 50 & 83.24 & \\
B & 27 & 163.15 & $3.18 \%$ \\
& 35 & 168.51 & \\
\hline
\end{tabular}

Table 2: $r_{s}^{d}$ at different aging time of column (sample A)

\begin{tabular}{cccc}
\hline $\begin{array}{c}\text { Inlet pressure } \\
(\mathrm{kPa})\end{array}$ & $\begin{array}{c}\text { Aging } \\
\text { time }(\mathrm{h})\end{array}$ & $\begin{array}{c}r_{s}^{d} \\
\left(\mathrm{~mJ} / \mathrm{m}^{2}\right)\end{array}$ & Error \\
\hline 30 & 12 & 85.05 & $4.6 \%$ \\
& 24 & 88.96 & \\
50 & 12 & 83.24 & $5.3 \%$ \\
\hline
\end{tabular}

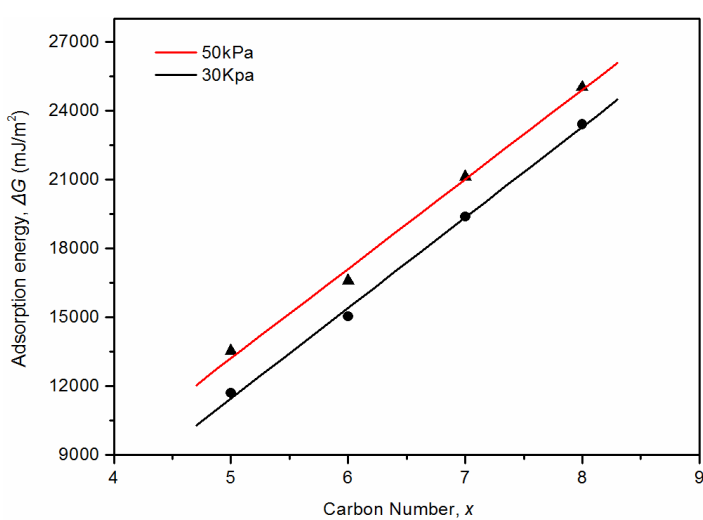

Figure 1: The effect of inlet pressure of column (Sample A)

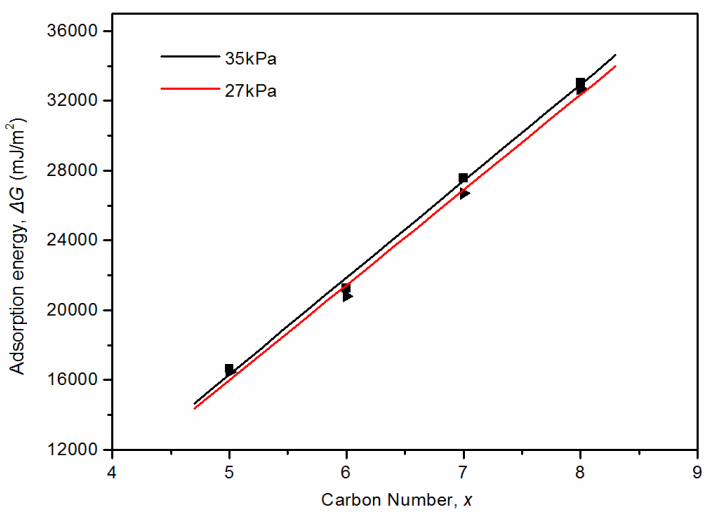

Figure 2: The effect of inlet pressure of column (Sample B)

As shown in Table 1, the dispersive free energy $r_{s}^{d}$ of sample A decreases from $85.05 \mathrm{~mJ} / \mathrm{m}^{2}$ at $30 \mathrm{kPa}$ to 83.24 $\mathrm{mJ} / \mathrm{m}^{2}$ at $50 \mathrm{kPa}$, and the error is $2.17 \%$. The dispersive free energy of sample B increases from $163.15 \mathrm{~mJ} / \mathrm{m}^{2}$ at $27 \mathrm{kPa}$ to $168.51 \mathrm{~mJ} / \mathrm{m}^{2}$ at $35 \mathrm{kPa}$, and the error is $3.18 \%$. These

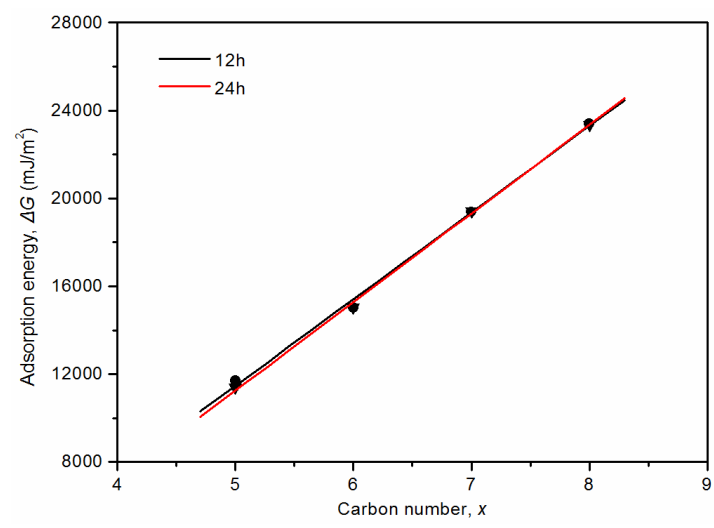

Figure 3: Effect of aging time of column on adsorption energy (30 $\mathrm{kPa})$

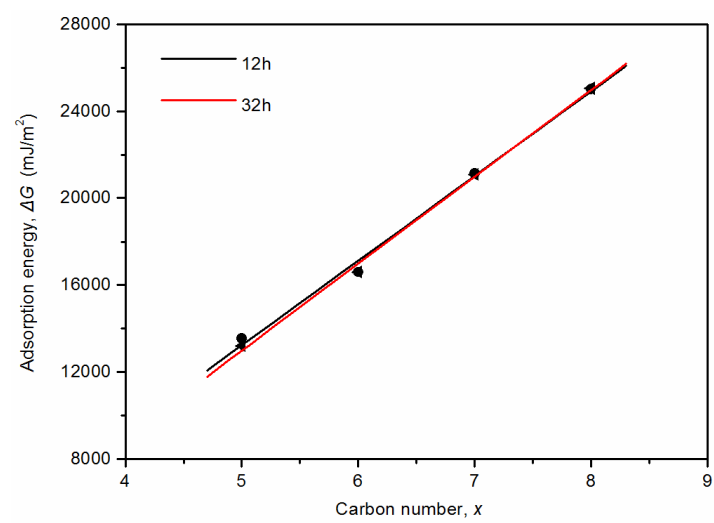

Figure 4: Effect of aging time of column on adsorption energy $(50 \mathrm{kPa})$

results indicate that the inlet pressure of column has little effect on the dispersive surface free energy of CB.

Figures 1 and 2 show that at different inlet pressures, the probe molecules have a good linear correlation between the adsorption free energy and the number of carbon atoms, and the slope $\left(-\Delta G_{\mathrm{CH}_{2}}\right)$ of different straight lines is almost identical. According to formula (4), $-\Delta G_{\mathrm{CH}_{2}}$ is an important parameter to calculate the dispersive free energy. The larger the $-\Delta G_{\mathrm{CH}_{2}}$, the greater the dispersive free energy. Therefore, we can conclude that the inlet pressure of column has little effect on the dispersive free energy of CB under the investigations by inverse gas chromatography.

\subsection{Effect of column aging time on surface free energy}

Table 2 shows the dispersive free energy $r_{s}^{d}$ of sample A at different aging time. Figures 3 and 4 show the relationship between the adsorption energy and the carbon num- 
ber of probe molecules at different aging times. The experimental condition was fixed at the column temperature of $180^{\circ} \mathrm{C}$, the carrier gas flow rate of $12.24 \mathrm{~mL} / \mathrm{min}$, while the aging time of column was varied.

Table 2 shows that the dispersive free energy after the aging time of 24 hours and 32 hours is $4.6 \%$ and 5.3\%, respectively, which is higher than the result from the aging time of $12 \mathrm{~h}$. Figures 3 and 4 show that the probe molecules have a good linear correlation between the free energy of adsorption and the number of carbon atoms at different aging time. However, the slopes of different lines are different, which indicates that the aging time has an impact on the $-\Delta G_{\mathrm{CH}_{2}}$. According to formula (4), $-\Delta G_{\mathrm{CH}_{2}}$ is an important parameter to calculate the dispersive free energy. Therefore, it can be concluded that the aging time has an impact on the dispersive free energy of $\mathrm{CB}$ when the surface free energy of CB is measured by inverse gas chromatography. The dispersive free energy increases with aging time. It can be explained by the fact that the longer the aging time, the cleaner the desorption of the adsorbed impurities on the surface of the $\mathrm{CB}$. Therefore, the dispersive free energy will increase to some extents depending on the aging time.

\subsection{Effect of carrier gas flow rate on dispersive free energy}

By changing the carrier gas flow rate, the dispersive free energy, $r_{s}^{d}$, was measured for samples A, B, C and D at the following conditions: the column temperature of $180^{\circ} \mathrm{C}$, aging time of $24 \mathrm{~h}$, and inlet pressure of $30 \mathrm{kPa}$. The values of dispersive free energy of different CBs were calculated based on the formula in Section 2.4 with errors below 2.5\% and the results are shown in Table 3. It can be reasonably concluded that the effect of the flow rates on each CB sample is almost negligible.

Table 3: $r_{s}^{d}$ at different carrier gas flow rates

\begin{tabular}{cccc}
\hline Sample & $D(\mathrm{~mL} / \mathrm{min})$ & $r_{s}^{d}\left(\mathrm{~mJ} / \mathrm{m}^{2}\right)$ & Error \\
\hline \multirow{2}{*}{ A } & 6.87 & 86.82 & $2.46 \%$ \\
& 12.24 & 88.96 & \\
B & 12.26 & 168.51 & $2.21 \%$ \\
& 131 & 164.78 & \\
C & 11.16 & 104.86 & $1.82 \%$ \\
& 20.22 & 106.77 & \\
D & 12.56 & 116.45 & $1.48 \%$ \\
& 21.51 & 118.17 & \\
\hline
\end{tabular}

\subsection{Effect of carrier gas flow rate on surface free energy}

According to the experimental results above, it can be seen that the influence of carrier gas flow rate on the free energy of a specific CB surface is below 2.5\%, which is almost negligible.

However, it seems that carrier gas flow rate makes some difference according to our experience on the basis of a large number of experimental measurements in the past few years. In order to clarify this point, four types of CB with different values of surface free energy have been tested.

\subsubsection{Adjusted retention time under different carrier gas flow rates}

By measuring the adjusted retention time under different carrier gas flow rates, the logarithm of the adjusted retention time is plotted against the number of carbon atoms for each n-alkane probe molecule, and the results are shown in Figures 5 to 8.

It should be noted that the retention time of n-octane is much longer than other n-paraffin hydrocarbons, due to the strong interaction between n-octane and CB surface. Furthermore, the shape of n-octane peak is also irregular, especially for samples with high surface energy. Therefore, the measurement of retention time using n-octane is canceled in this test to avoid some obvious errors and unnecessary time consumption.

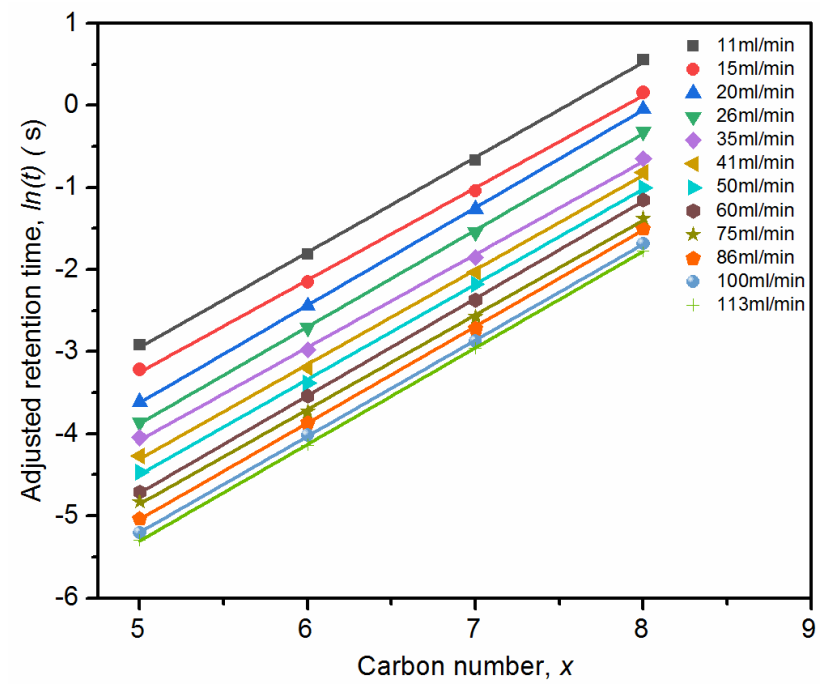

Figure 5: Adjustment retention time of probe molecules for sample N550 


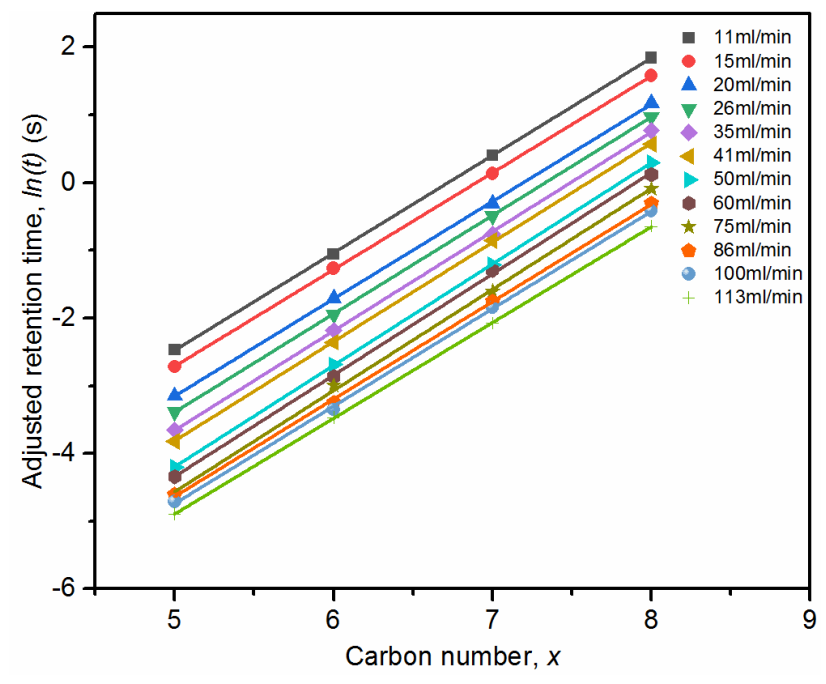

Figure 6: Adjustment retention time of probe molecules for sample N375

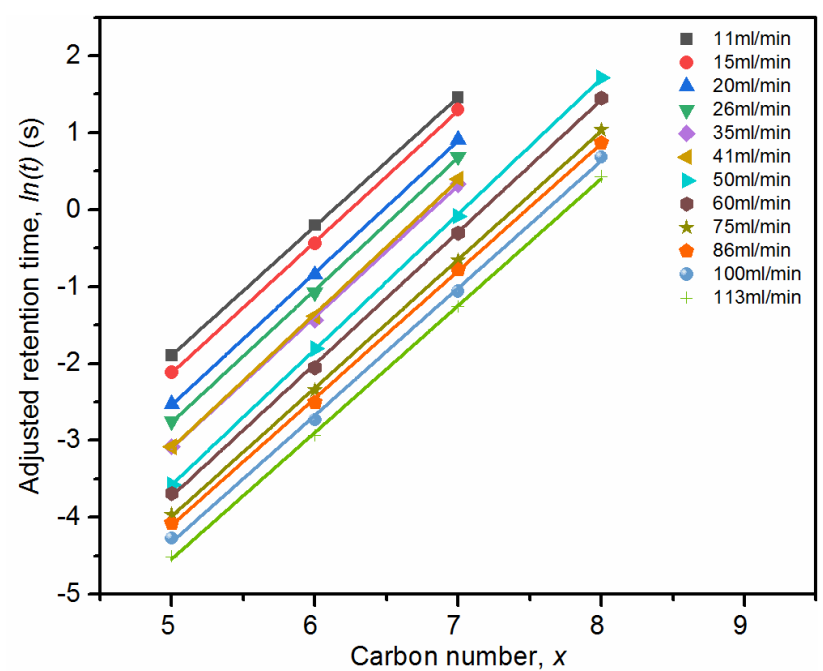

Figure 7: Adjustment retention time of probe molecules for sample N $375-300^{\circ} \mathrm{C}$

From Figure 5 to Figure 8, it can be seen that the logarithmic values of the adjusted retention time of each $n$ alkane probe molecule obey a good linear relationship with the carbon numbers at different carrier gas flow rates. In addition, for the same kind of CB samples, the straight lines at different flow rates maintain a good parallel relationship, that is, the straight line slope $\left(-\Delta G_{\mathrm{CH}_{2}}\right)$ is nearly identical. According to equation (4), the dispersive free energy of the CB surface is almost unchanged, indicating that the carrier gas flow rate has little effect on the dispersive free energy of CB surface.

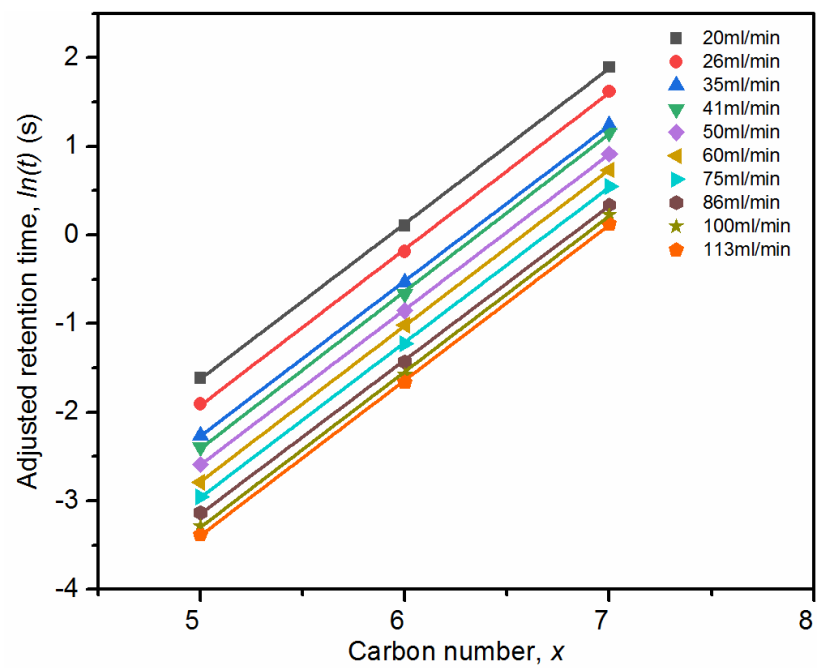

Figure 8: Adjustment retention time of probe molecules for sample N234

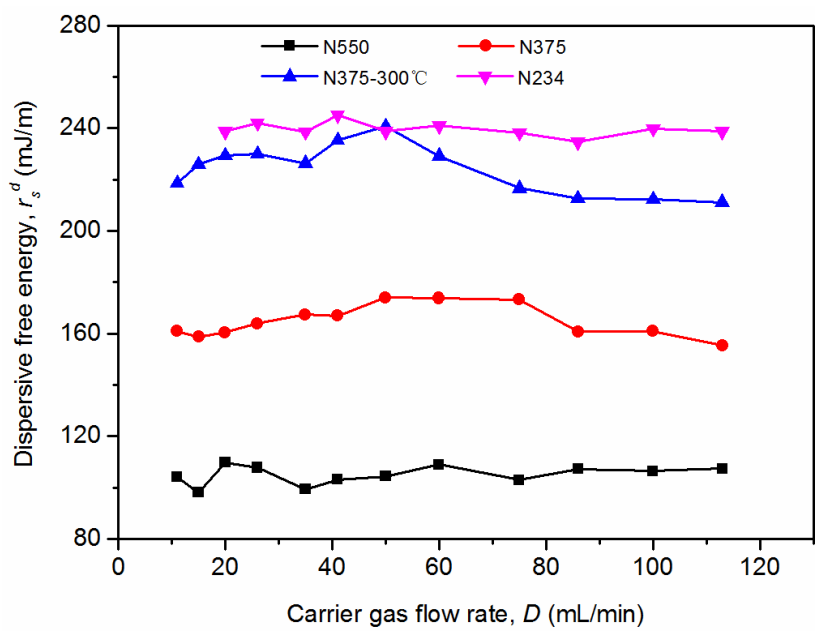

Figure 9: Dispersive free energy of different samples versus carrier gas flow rate

\subsubsection{Surface free energy at different carrier gas flow rates}

According to formula (1) to formula (5), the CB surface free energy of four samples was calculated at different carrier gas flow rates, and the results are summarized in Table 4. The dispersive free energy and polar parameter of different CB samples versus the carrier gas flow are shown in Figures 9 and 10. The surface free energy is shown in Figure 11.

It can be seen that the relative standard deviations (RSD) from Table 4 are below $5 \%$ for all CB samples. Accordingly, the change of carrier gas flow rate has no obvious effect on the surface free energy of CB. It is also indicative from Figure 9 that the trends of dispersive free en- 
Table 4: CB surface free energy measured at different carrier gas flow rates

\begin{tabular}{ccccccccc}
\hline & \multicolumn{3}{c}{ Dispersive free energy $\left(\mathrm{mJ} / \mathrm{m}^{2}\right)$} & \multicolumn{3}{c}{ Polar parameter $\left(\mathrm{mJ} / \mathrm{m}^{2}\right)$} \\
\hline CGFR Samples & $\mathrm{N} 550$ & $\mathrm{~N} 375$ & $\mathrm{~N} 375-300{ }^{\circ} \mathrm{C}$ & $\mathrm{N} 234$ & $\mathrm{~N} 550$ & $\mathrm{~N} 375$ & $\mathrm{~N} 375-300{ }^{\circ} \mathrm{C}$ & $\mathrm{N} 234$ \\
\hline 11 & 104.1 & 160.9 & 218.7 & - & 56.6 & 57.5 & 74.2 & - \\
15 & 98.1 & 158.7 & 225.9 & - & 54.1 & 62.9 & 75.9 & - \\
20 & 109.8 & 160.5 & 229.3 & 238.8 & 60.9 & 62.8 & 76.1 & 72.1 \\
26 & 107.8 & 164.0 & 230.0 & 242.0 & 59.1 & 64.1 & 76.0 & 72.9 \\
35 & 99.4 & 167.4 & 226.3 & 238.6 & 59.7 & 63.5 & 76.6 & 72.2 \\
41 & 103.1 & 166.9 & 235.3 & 245.1 & 59.0 & 62.1 & 78.6 & 73.7 \\
50 & 104.4 & 174.1 & 240.8 & 238.8 & 60.8 & 62.3 & 82.0 & 72.9 \\
60 & 109.0 & 173.8 & 229.2 & 241.0 & 61.0 & 67.6 & 79.8 & 74.3 \\
75 & 103.0 & 173.3 & 216.6 & 238.3 & 56.9 & 68.5 & 76.9 & 73.1 \\
86 & 107.2 & 160.8 & 212.7 & 234.6 & 61.0 & 62.4 & 77.7 & 72.8 \\
100 & 106.4 & 160.9 & 212.3 & 239.9 & 62.5 & 64.9 & 76.5 & 74.5 \\
113 & 107.4 & 155.4 & 211.2 & 238.7 & 60.9 & 64.2 & 77.5 & 74.2 \\
Max. Value & 109.8 & 174.1 & 240.8 & 245.1 & 62.5 & 68.5 & 82.0 & 74.5 \\
Min. Value & 98.1 & 155.4 & 211.2 & 234.6 & 54.1 & 57.5 & 74.2 & 72.1 \\
Average Value & 105.0 & 164.7 & 224.0 & 239.6 & 59.4 & 63.6 & 77.3 & 73.3 \\
RSD & $3.5 \%$ & $3.8 \%$ & $4.3 \%$ & $1.1 \%$ & $4.1 \%$ & $4.4 \%$ & $2.7 \%$ & $1.2 \%$ \\
\hline
\end{tabular}

(CGFR: Carrier gas flow rate, $\mathrm{mL} / \mathrm{min}$; RSD: relative standard deviation)

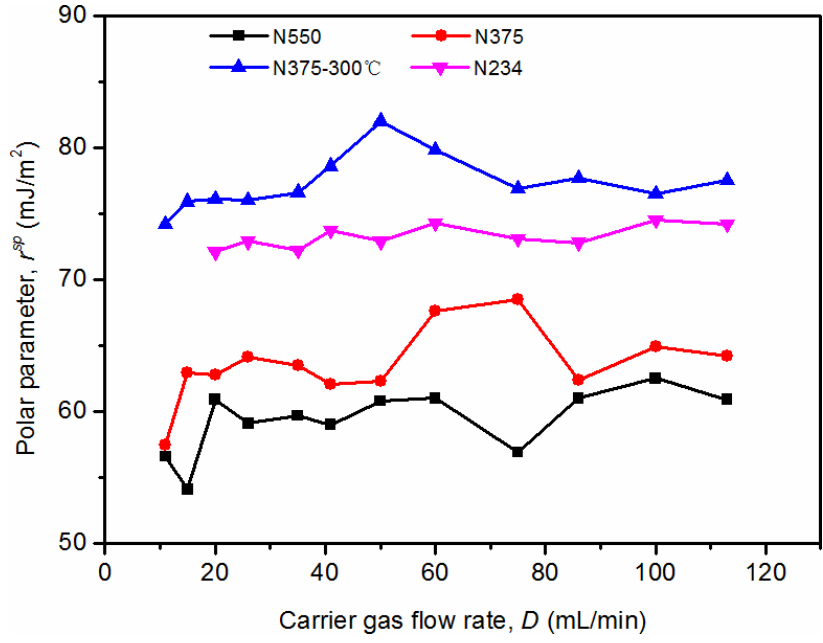

Figure 10: Polar parameter of different samples versus carrier gas flow rate

ergy for different CB samples are consistent at different carrier gas flow rates, demonstrating that the influence of carrier gas flow rate on the dispersive free energy of different CB samples is the same. According to Figure 10, in case of the slow carrier gas flow rate, the vibration values of N550 and N375 are large. Consequently, small carrier gas flow rate should be avoided during experimental measurements. Under the condition of higher carrier gas flow rate, the fluctuation of the polar parameters is smaller, indicating that the influence of the carrier gas flow rate on the po-

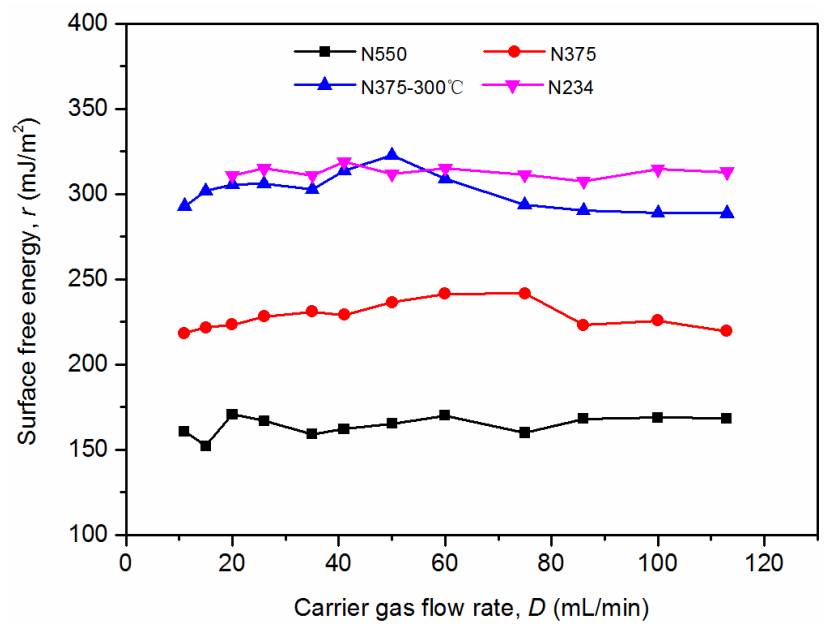

Figure 11: Surface free energy of different samples versus carrier gas flow rate

lar parameter of $\mathrm{CB}$ is not significant. According to the data of $\mathrm{N} 375$ and $\mathrm{N} 375-300^{\circ} \mathrm{C}$, we know both dispersive free energy and polar parameter of $\mathrm{N} 375 \mathrm{CB}$ after $300^{\circ} \mathrm{C}$ treatment have a significant increase of about $36 \%$ compared with the results from untreated $\mathrm{CB}$, which indicates that the surface free energy of $\mathrm{CB}$ will change after heating. However, no matter the CBs have been heated or not, the effect of carrier gas flow rate on the experimental results is not significant when the surface free energy is measured by inverse gas chromatography. 
Table 5: Effect of heat treatment on surface free energy of CB

\begin{tabular}{cccc}
\hline & $\begin{array}{c}r_{s}^{d} \\
\left(\mathrm{~mJ} / \mathrm{m}^{2}\right)\end{array}$ & $\begin{array}{c}r^{s p} \\
\left(\mathrm{~mJ} / \mathrm{m}^{2}\right)\end{array}$ & $r\left(\mathrm{~mJ} / \mathrm{m}^{2}\right)$ \\
\hline N660 (untreated) & 123.14 & 63.24 & 186.38 \\
N660 $\left(300^{\circ} \mathrm{C}\right)$ & 273.52 & 70.35 & 343.87 \\
$\mathrm{~N} 660\left(400^{\circ} \mathrm{C}\right)$ & 323.24 & 80.52 & 403.76 \\
$\mathrm{~N} 660\left(500^{\circ} \mathrm{C}\right)$ & 389.45 & 87.43 & 476.90 \\
\hline
\end{tabular}

According to Figure 11, it can be seen that the trends of surface free energy are very similar for any types of CB samples, indicating that the effect of carrier gas flow rate on the surface free energy is insignificant.

\subsection{Effect of heat treatment of CB on rubber performance}

According to the comparison of $\mathrm{CB} \mathrm{N} 375$ and $\mathrm{N} 375-300^{\circ} \mathrm{C}$, the surface free energy of $\mathrm{CB}$ has a significant increase after heat treatment at high temperature. The surface free energy (surface activity) is a major factor affecting the reinforcement of rubber. Therefore, it is important to further investigate the effect of heat treatment on the performance of the rubber reinforced by $\mathrm{CB}$. We performed a series of experiment, the industrial CB N660 was subjected to vacuum heat treatment at different temperatures, and applied in SRB rubber. The performance of the reinforced rubber was tested.

\subsubsection{Effect of heat treatment on surface free energy of CB}

The dispersive free energy and polarity parameters of CB N660 increase with the increase of temperature (Table 5). The dispersive free energy increases particularly fast, which leads to the increase of CB surface free energy. It can be concluded that temperature has an important effect on the surface activity of CB. It may be due to the reduction of surface adsorbates and some highly active sites exposed after heat treatment [35].

\subsubsection{Effect of heat-treated CB on Mooney viscosity and vulcanization}

It can be seen from Table 6 that for the rubber filled by CB N660 the maximum torque MH during vulcanization is gradually reduced from 20.89 to 18.54 with the increasing

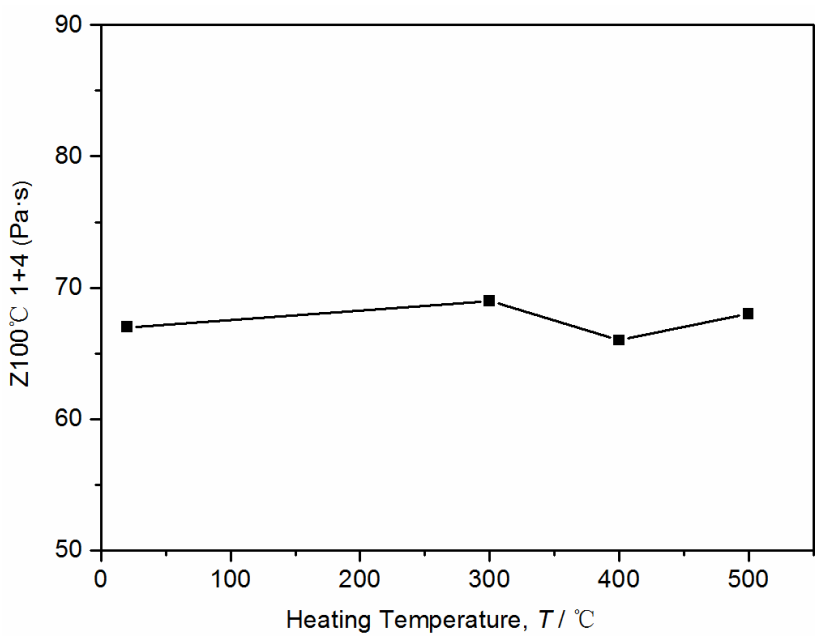

Figure 12: Effect of high temperature treatment on Mooney viscosity for carbon black filled SBR rubber

treatment temperature of $\mathrm{CB}$, while the scorching time $\mathrm{T}_{10}$ and the positive vulcanization time $\mathrm{T}_{90}$ change little. The main effect of heat treatment on the $\mathrm{CB}$ is the reduction of the surface active groups on CB surface which affects the surface properties of $\mathrm{CB}$. Therefore, the maximum torque $\mathrm{MH}$ is affected, while it has little effect on the curing time.

It can be seen from Figure 12 that the Mooney viscosity of the rubber filled with $\mathrm{CB}$ N660 has little change after treatment at $300^{\circ} \mathrm{C}, 400^{\circ} \mathrm{C}$ and $500^{\circ} \mathrm{C}$. The $\mathrm{CB}$ undergoes high temperature treatment, which could affect the surface activity and reduce the active groups on the surface of CB. However, heat treatment has little effect on the particle size and pore structure of CB. Therefore, the bound rubber content in the blend is not influenced significantly.

\subsubsection{Effect of heat-treated CB on mechanical properties of vulcanizate}

It can be seen from Table 7 that when the industrial CB N660 is subjected to high-temperature treatment, the tensile strength of the reinforced rubber after vulcanization changes little, the tensile stress is slightly reduced, and the tear strength, hardness and resilience energy are not changed obviously, while the elongation at break has an increasing trend. The reason is that the active groups on the surface of the particles was changed after hightemperature treatment. However, the size and structure of CB changed little. Therefore, the tensile stress of vulcanized rubber was reduced and the elongation at break was increased. 
Table 6: Effect of high temperature treatment of $C B$ on vulcanization characteristics of gross rubber

\begin{tabular}{ccccc}
\hline & $\begin{array}{c}\text { Minimum torque } \\
\left(\mathrm{M}_{L} / \mathrm{dN} \cdot \mathrm{m}\right)\end{array}$ & $\begin{array}{c}\text { Maximum torque } \\
\left(\mathrm{M}_{H} / \mathrm{dN} \cdot \mathrm{m}\right)\end{array}$ & $\begin{array}{c}\text { Scorching time } \\
\left(\mathrm{T}_{10} / \mathrm{min}\right)\end{array}$ & $\begin{array}{c}\text { Positive vulcanization } \\
\text { time }\left(\mathrm{T}_{90} / \mathrm{min}\right)\end{array}$ \\
\hline N660 (untreated) & 2.19 & 20.89 & 15.60 & 37.25 \\
$\mathrm{~N} 660\left(300^{\circ} \mathrm{C}\right)$ & 2.28 & 20.10 & 16.71 & 39.30 \\
$\mathrm{~N} 660\left(400^{\circ} \mathrm{C}\right)$ & 2.22 & 19.51 & 17.05 & 37.91 \\
$\mathrm{~N} 660\left(500^{\circ} \mathrm{C}\right)$ & 2.23 & 18.54 & 15.60 & 39.11 \\
\hline
\end{tabular}

Table 7: Effect of high temperature treatment of $\mathrm{N} 660$ CB on physical and mechanical properties of vulcanizate

\begin{tabular}{ccccc}
\hline & $\mathrm{N} 660$ (untreated) & $\mathrm{N} 660\left(300^{\circ} \mathrm{C}\right)$ & $\mathrm{N} 660\left(400^{\circ} \mathrm{C}\right)$ & $\mathrm{N} 660\left(500^{\circ} \mathrm{C}\right)$ \\
\hline Tensile strength (MPa) & 19.82 & 21.28 & 21.52 & 21.97 \\
Strength at 100\% elongation (MPa) & 2.52 & 2.49 & 2.38 & 2.34 \\
Strength at 300\% elongation (MPa) & 12.42 & 12.11 & 11.65 & 11.75 \\
Elongation at break (\%) & 495 & 512 & 545 & 553 \\
Tear strength (MPa) & 46.7 & 50.2 & 47.8 & 48.6 \\
Hardness (Shore A) & 66 & 66 & 66 & 65 \\
Resilience (\%) & 45.5 & 45.7 & 45.4 & 45.6 \\
\hline
\end{tabular}

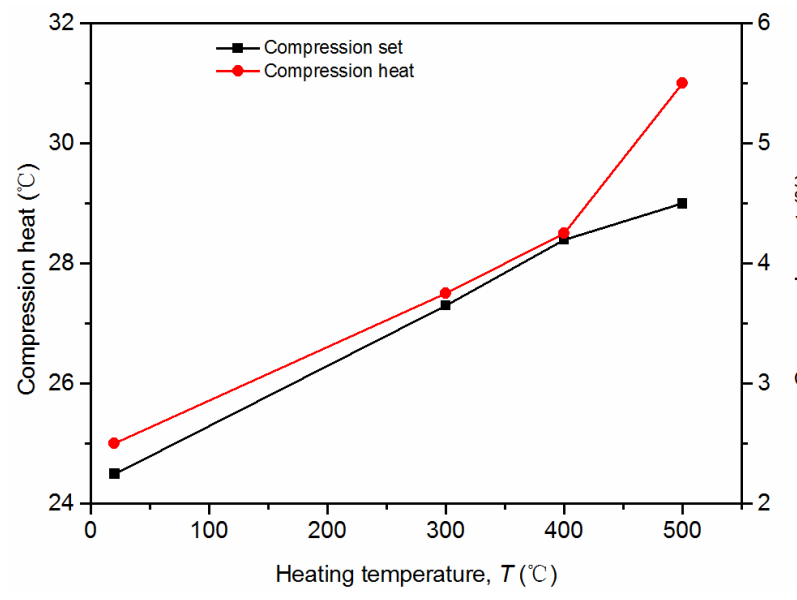

Figure 13: Compression heat and compression set versus temperature of vulcanized rubber filled with N660

The compression heat and compression set of SBR reinforced by N660 increase with the increase of temperature (Figure 13). The reason could be that the hightemperature treatment weakened the surface activity of the $\mathrm{CB}$, so that the interaction among the $\mathrm{CB}$ particles and the rubber polymer chains is weakened. The molecular chains and the CB particles cannot simultaneously move, resulting in hysteresis under the changing stress, which enhanced the friction between the $\mathrm{CB}$ and rubber. As a result, the heat generation was increased, and also the permanent deformation rate.

The abradability of the vulcanized rubbers filled with the CB N660 was tested using a DIN (German Industrial

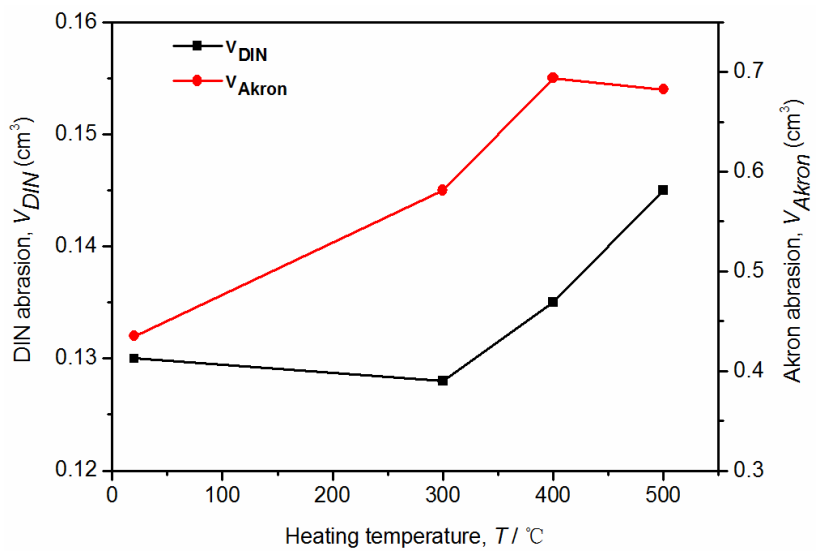

Figure 14: Effect of temperature on abradability of vulcanized rubber filled with $\mathrm{N} 660$

Standard) and an Akron abrasion machine. The results in Figure 14 show that the abrasion value of vulcanized rubber increases with the increase of temperature, which is due to the decrease of surface activity of CB particles, leading to the decrease of interaction between $\mathrm{CB}$ particles and rubber molecular chains. As a result, the wear resistance of vulcanized rubber decreased.

\section{Conclusions}

The surface free energy of $\mathrm{CB}$ was measured by inverse gas chromatography and a formula was proposed to calculate 
the surface free energy through theoretical derivation. The following conclusions could be drawn.

1. The inlet pressure and the carrier gas flow rate of the column have little effect on the dispersive free energy, and the variation trend of dispersive free energy and polar parameters with carrier gas flow rate are basically consistent. The aging time of the chromatographic column has a certain influence on the experimental results, since the adsorbates on the $\mathrm{CB}$ surface will be reduced as the aging time increases.

2. The high-temperature treatment of industrial CB has little influence on its structure, while mainly affects the surface activity of CB. The Mooney viscosity, the scorching time and vulcanization rate of the blend are affected little by the high-temperature treatment of $\mathrm{CB}$. However, the maximum torque is decreased significantly with the increase of temperature.

3. With the increase of heating temperature for $\mathrm{CB}$, the change of tensile strength and stress at definite elongation of CB-reinforced SBR is small, the elongation at break tends to increase, the heat generation of vulcanizates is increased, while the wear resistance is decreased.

Data Availability: The data used to support the findings of this study are included within the article. Any more specific details in the data will be delivered by the corresponding author upon request.

Conflict of Interest: The authors declare no conflict of interest regarding the publication of this paper.

Acknowledgement: This research was financially supported by Minjiang Scholarship of Fujian Province (No. Min-Gaojiao[2010]-117), Central-government Guided Fund for Local Economic Development (No. 830170778), R\&D Fund for Strategic Emerging Industry of Fujian Province (No. 82918001), International Cooperation Project of Fujian Science and Technology Department (No. 830170771) and Teaching and Researching Fund for Young Staff of Fujian Educational Department (No. JT180040).

\section{References}

[1] Hoshikawa Y., An B., Kashihara S., Ishii T., Ando M., Fujisawa S., Hayakawa K., Hamatani S., Yamada H., Kyotani T., Analysis of the interaction between rubber polymer and carbon black surfaces by efficient removal of physisorbed polymer from carbon-rubber composites, Carbon, 2016, 99, 148-156.

[2] Wang F., Hong R. Y., Feng W. G., Badami D., Zeng K., Electrical and mechanical properties of ABS/EPDM composites filled with carbon black, Mater. Lett., 2014, 125, 48-50.

[3] Ossai C. I., Raghavan N., Nanostructure and nanomaterial characterization, growth mechanisms, and applications, Nanotechnol. Rev., 2018, 7, 209-231.

[4] Jaffe A., Valdes A. S., Karunadasa H. I., Quinone-functionalized carbon black cathodes for lithium batteries with high power densities, Chem. Mater., 2015, 27, 3568-3571.

[5] Power A. C., Gorey B., Chandra S., Chapman J., Carbon nanomaterials and their application to electrochemical sensors: a review, Nanotechnol. Rev., 2018, 7, 19-41.

[6] Kameya Y., Hayashi T., Motosuke M., Stability of platinum nanoparticles supported on surface-treated carbon black, Appl. Catal. B-environ, 2016, 189, 219-225.

[7] Yuan J. J., Hong R. Y., Wang Y. Q., Feng W. G., Low-temperature plasma preparation and application of carbon black nanoparticles, Chem. Eng. J., 2014, 253, 107-120.

[8] Roy S., Petrova R. S., Mitra S., Effect of carbon nanotube (CNT) functionalization in epoxy-CNT composites, Nanotechnol. Rev., 2018, 7, 475-485.

[9] Yeo K. K., Oxidation and surface functional group analyses under ozone treatment of carbon black, Elastomers and Composites, 2005, 40, 188-195.

[10] Jiang D., Wang C., Jiang Z., Zhou W., Zhang F., Influences of dispersants with different structures on the dispersibility of carbon black, Chinese J. Process Eng., 2015, 15, 153-158.

[11] Xiao F., Bedane A. H., Zhao J. X., Mann M. D., Pignatello J. J., Thermal air oxidation changes surface and adsorptive properties of black carbon (char/biochar), Sci. Total. Environ., 2018, 618, 276-283.

[12] Morales-Lara F., Domingo-Garcia M., Lopez-Garzon R., Luz Godino-Salido M., Penas-Sanjuan A., Javier Lopez-Garzon F., Perez-Mendoza M., Melguizo M., Grafting the surface of carbon nanotubes and carbon black with the chemical properties of hyperbranched polyamines, Sci. Technol. Adv. Mat., 2016, 17, 541-553.

[13] Xia Y., Kuanjun F., Procedures of hydrophilic modification of carbon black surface, Chem. Ind. Eng. Pro., 2007, 26, 657-663.

[14] Sun D. L., Hong R. Y., Wang F., Liu J. Y., Rajesh Kumar M., Synthesis and modification of carbon nanomaterials via $\mathrm{AC}$ arc and dielectric barrier discharge plasma, Chem. Eng. J., 2016, 283, 9-20.

[15] Zhang Z., An Y., Nanotechnology for the oil and gas industry - an overview of recent progress, Nanotechnol. Rev., 2018, 7, 341-353.

[16] Raos G., Application of the Christensen-Lo model to the reinforcement of elastomers by fractal fillers, Macromol. Theor. Simul, 2003, 12, 17-23.

[17] Dannenberg E. M., Bound rubber and carbon-black reinforcement, Rubber Chem. Technol., 1986, 59, 512-524.

[18] Bandaru P. R., Yamada H., Narayanan R., Hoefer M., The role of defects and dimensionality in influencing the charge, capacitance, and energy storage of graphene and 2D materials, Nanotechnol. Rev., 2017, 6, 421-433.

[19] Kim S. M., Kim K. J., Thiazole type accelerator effects on silane/silica filled natural rubber compound upon vulcanization and mechanical properties, Polym-Korea, 2012, 36, 235-244.

[20] Zhang H., Xie J., An S., Qian X., Cheng H., Zhang F., Li X., A novel measurement of contact angle on cylinder-shaped lignocellu- 
losic fiber for surface wettability evaluation, Colloid Surface. A, 2018, 540.

[21] Papirer E., Brendle E., Ozil F., Balard H., Comparison of the surface properties of graphite, carbon black and fullerene samples, measured by inverse gas chromatography, Carbon, 1999, 37, 1265-1274.

[22] Mills R. H., Jara R., Gardner D. J., van Heiningen A., Inverse gas chromatography for determining the surface free energy and acid-base chemical characteristics of a water extracted hardwood (Acer rubrum), J. Wood. Chem. Technol., 2009, 29, 11-23.

[23] Lam C. N. C., Wu R., Li D., Hair M. L., Neumann A. W., Study of the advancing and receding contact angles: liquid sorption as a cause of contact angle hysteresis, Adv. Colloid Interfac, 2002, 96, 169-191.

[24] Adao M., Saramago B. J. V., Fernandes A. C., Estimation of the surface properties of styrene-acrylonitrile random copolymers from contact angle measurements, J. Colloid Interf. Sci, 1999, 217, 94-106.

[25] Kozbial A., Li Z., Conaway C., McGinley R., Dhingra S., Vahdat V., Zhou F., D'Urso B., Liu H., Li L., Study on the surface energy of graphene by contact angle measurements, Langmuir., 2014, 30, 8598-8606.

[26] Chibowski E., Perea-Carpio R., Problems of contact angle and solid surface free energy determination, Adv. Colloid Interfac, 2002, 98, 245-264.

[27] Voelkel A., Strzemiecka B., Adamska K., Milczewska K., Inverse gas chromatography as a source of physiochemical data, J. Chromatogr. A, 2009, 1216, 1551-1566.

[28] Mohammadi-Jam S., Waters K. E., Inverse gas chromatography applications: A review, Adv. Colloid Interf., 2014, 212, 21-44.
[29] Menzel R., Bismarck A., Shaffer M. S. P., Deconvolution of the structural and chemical surface properties of carbon nanotubes by inverse gas chromatography, Carbon, 2012, 50, 3416-3421.

[30] Peng Y., Gardner D. J., Han Y., Cai Z., Tshabalala M. A., Influence of drying method on the surface energy of cellulose nanofibrils determined by inverse gas chromatography, J. Colloid Interf. Sci, 2013, 405, 85-95.

[31] Darmstadt H., Cao N. Z., Pantea D. M., Roy C., Summchen L., Roland U., Donnet J. B., Wang T. K., Peng C. H., Donnelly P. J., Surface activity and chemistry of thermal carbon blacks, Rubber Chem. Technol., 2000, 73, 293-309.

[32] Castellano M., Falqui L., Costa G., Turturro A., Valenti B., Castello $G$., Investigation on elastomer-silica interactions by inverse gas chromatography and image analysis aided transmission electron microscopy, J. Macromol. Sci. Phys., 2002, B41, 451-471.

[33] Wang M. J., Tu H. R., Murphy L. J., Mahmud K., Carbon-silica dual phase filler, a new generation reinforcing agent for rubber: Part VIII. Surface characterization by IGC, Rubber Chem. Technol., 2000, 73, 666-677.

[34] Gamble J. F., Leane M., Olusanmi D., Tobyn M., Supuk E., Khoo J., Naderi M., Surface energy analysis as a tool to probe the surface energy characteristics of micronized materials-A comparison with inverse gas chromatography, Int. J. Pharm., 2012, 422, 238 244.

[35] Li Z., Xu K., Pan Y., Recent development of supercapacitor electrode based on carbon materials, Nanotechnol. Rev., 2019, 8, 35-49. 